\title{
Interpretation of deformed ionograms induced by vertical ground motion of seismic Rayleigh waves and infrasound in the thermosphere
}

\author{
Takashi Maruyama ${ }^{1,2}$, Kamil Yusupov $^{2}$, and Adel Akchurin ${ }^{2}$ \\ ${ }^{1}$ National Institute of Information and Communications Technology, Tokyo, Japan \\ ${ }^{2}$ Kazan Federal University, Kazan, Russia \\ Correspondence to: Takashi Maruyama (tmaru@ nict.go.jp)
}

Received: 28 December 2015 - Revised: 26 January 2016 - Accepted: 27 January 2016 - Published: 18 February 2016

\begin{abstract}
The vertical ground motion of seismic surface waves launches acoustic waves into the atmosphere and induces ionospheric disturbances. Disturbances due to Rayleigh waves near the short-period Airy phase appear as wavy fluctuations in the virtual height of an ionogram and have a multiple-cusp signature (MCS) when the fluctuation amplitude is increased. An extremely developed MCS was observed at Kazan, Russia, after the 2010 M 8.8 Chile earthquake. The ionogram exhibited steep satellite traces for which the virtual heights increased rapidly with frequency starting near the top of cusps and continuing for $0.1-0.2 \mathrm{MHz}$. This complicated ionogram was analyzed by applying a ray tracing technique to the radio wave propagation in the ionosphere that was perturbed by acoustic waves. Acoustic wavefronts were inclined by the effects of finite Rayleigh wave velocity and sound speed in the thermosphere. The satellite echo traces were reproduced by oblique returns from the inclined wavefronts, in addition to the nearly vertical returns that are responsible for the main trace.
\end{abstract}

Keywords. Ionosphere (ionosphere-atmosphere interactions; ionospheric irregularities) - radio science (radio wave propagation)

\section{Introduction}

It is widely known that a variety of ionospheric disturbances are induced after large earthquakes as a result of lithosphereatmosphere-ionosphere coupling (Blanc, 1985; Rolland et al., 2011). The vertical ground motion of seismic waves launches acoustic waves into the atmosphere. The dominant seismic wave energy at remote distances is associated with the short-period Airy phase of Rayleigh waves with a period of 10 to $50 \mathrm{~s}$ (Oliver, 1962), which propagates over long distances with little dissipation compared to other wave modes. As the excited infrasound signals propagate upward, their amplitudes increase due to the conservation of momentum in the density-rarefied atmosphere (e.g., Chum et al., 2012; Maruyama and Shinagawa, 2014). Infrasound signals with periods longer than $\sim 15 \mathrm{~s}$ reach ionospheric altitudes (Tanaka et al., 1984) and interact with ions through neutralion collisions. At ionospheric altitudes, sound speed is 500 to $1000 \mathrm{~m} \mathrm{~s}^{-1}$, yielding vertical wavelengths of 7.5 to $50 \mathrm{~km}$. Because the vertical wavelengths of the induced ionospheric disturbances are shorter than the bottomside thickness of the ionosphere, electron density disturbances are not detected by total electron content measurements; however, ionogram traces are deformed instead.

Coseismic ionogram deformation was first reported by Leonard and Barnes (1965) following the M9.2 Alaska earthquake of 28 March 1964. The ionogram sketches exhibited complicated cusp-like (sharp edge upward) deformation in the virtual height throughout the $\mathrm{F}$ region. While, Yuen et al. (1969) reported sinusoidal fluctuations, or wiggles, in the F1 layer, associated with the 1968 Hachinohe (Tokachi-oki) earthquake in Japan. After the $2011 M 9.0$ Tohoku-oki earthquake in Japan, weak sinusoidal fluctuations to sharp cusptype deformations were observed in ionograms (Maruyama et al., 2011). These differences in the significance of ionogram disturbances were dependent on the amplitudes of the Rayleigh waves that were responsible for them (Maruyama et al., 2012; Maruyama and Shinagawa, 2014). 
An extreme case of cusp-type deformation was observed in an ionogram from Kazan, Russia, after the 2010 M 8.8 Chile earthquake. In addition to the cusp-shaped main trace, long-range satellite traces were observed, which started near the top of the cusps and with a virtual height that increased quickly with frequency. This paper interprets this extremely deformed ionogram showing a multipath signature. In Sect. 2, ionograms are presented for several levels of disturbances. Section 3 describes a model of electron density perturbations. Section 4 is the interpretation of the extreme deformation using ray tracing calculations. Section 5 summarizes the results.

\section{Observations}

The magnitude 8.8 earthquake $\left(35.91^{\circ} \mathrm{S}, 72.73^{\circ} \mathrm{W}\right)$ occurred at 06:34:14 UTC on 27 February 2010 off the coast of Chile. Associated with the earthquake, large-amplitude Rayleigh waves were observed at Obninsk $\left(55.11^{\circ} \mathrm{N}, 36.57^{\circ} \mathrm{E}\right.$; epicentral distance $14375 \mathrm{~km}$ ) near Moscow, Russia, at around 07:37 UTC, approximately 63 min after the earthquake, as shown in Fig. 1. The velocity of the Rayleigh waves was estimated at $3.8 \mathrm{~km} \mathrm{~s}^{-1}$. The ionosonde was operated at $1 \mathrm{~min}$ intervals at a sweep rate of $0.36 \mathrm{MHz} \mathrm{s}^{-1}$ at Kazan $\left(55.85^{\circ} \mathrm{N}\right.$, $48.81^{\circ} \mathrm{E}$; epicentral distance $15148 \mathrm{~km}$ ). The first coseismic ionospheric disturbance was recognized as a slightly kinked ionogram trace in the F1 region at 07:48 UTC (Maruyama et al., 2016). The difference between the epicentral distances for Obninsk and Kazan was approximately $773 \mathrm{~km}$. Thus, it is inferred that the ground motion of the Rayleigh waves at Kazan was delayed by $\sim 3.4$ min after Obninsk and is estimated to have started at around 07:40 UTC. Excited acoustic waves took an additional $\sim 7.6 \mathrm{~min}$ to reach ionospheric elevations. By 07:51 UTC, the distorted ionograms developed a multiple-cusp signature (MCS) and reached extremes at 08:00 UTC with a multipath effect. The MCS ionograms continued until at least 08:30 UTC.

Figure 2a shows an undisturbed ionogram obtained at 07:46 UTC just before the arrival of Rayleigh waves as shown in Fig. 1. The two cusps below $3 \mathrm{MHz}$ correspond to the critical frequencies of the $\mathrm{E}$ and $\mathrm{E} 2$ (or intermediate) layers. A moderate $\mathrm{F} 1$ cusp is seen near $3.9 \mathrm{MHz}$. The ionogram in Fig. 2b was obtained in the coda at 08:14 UTC and exhibits sinusoidal variation in virtual height caused by small-amplitude Rayleigh waves as shown in Fig. 1. Figure $2 \mathrm{c}$ shows a highly developed MCS ionogram with satellite traces that start near the top of the cusps and whose virtual height increased quickly with increasing frequency over $0.1-0.2 \mathrm{MHz}$. Note that the wave amplitude of ground motion at Obninsk varied periodically with a period of $2-3 \mathrm{~min}$ as shown in Fig. 1, which may be due to the interference of the Rayleigh waves propagating along different paths due to refraction (Capon, 1970), and the envelope of the amplitude modulation may not be the same at Obninsk and Kazan.

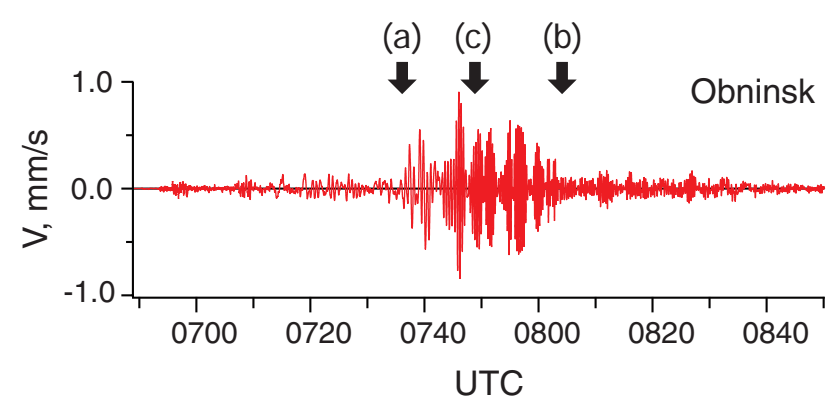

Figure 1. Vertical ground motion of 2010 Chile earthquake observed at Obninsk. Arrows (a), (b), and (c) correspond to ionograms shown in Fig. 2. To relate the seismogram to ionograms, times are shifted by $11 \mathrm{~min}$, taking account of propagation times of Rayleigh waves from Obninsk to Kazan and acoustic waves from the ground to ionospheric elevations.
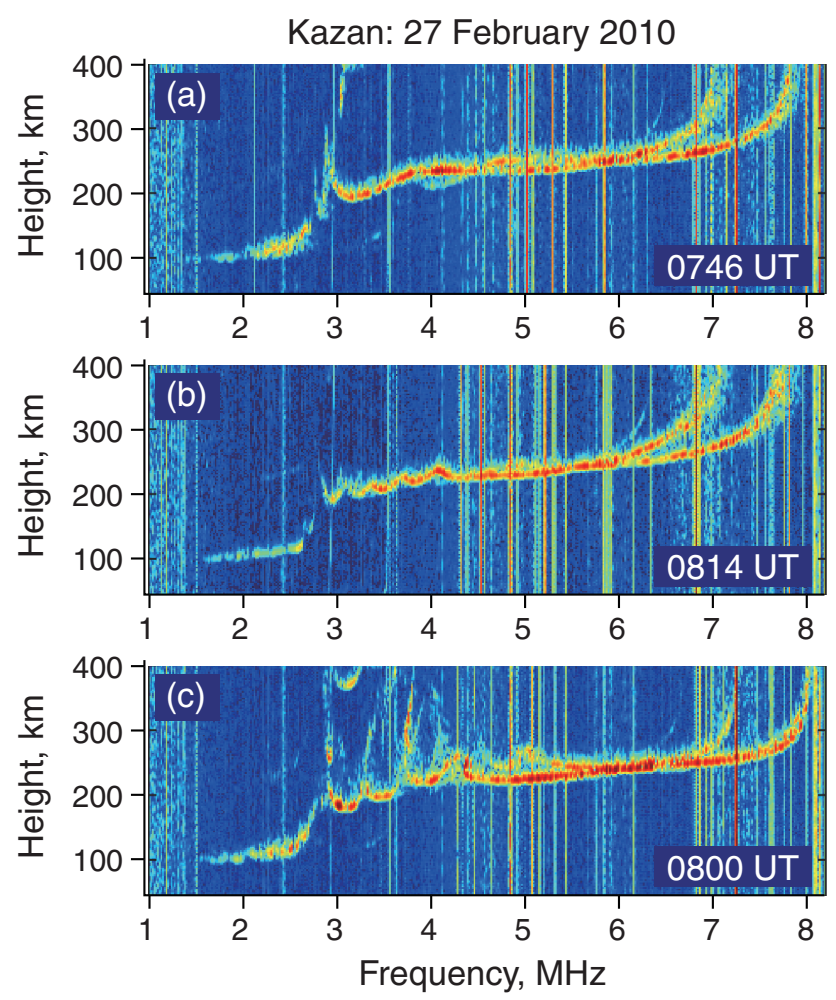

Figure 2. Ionograms obtained at Kazan showing unperturbed traces (a), weak coseismic disturbances (b), and a significant anomaly due to large amplitude acoustic waves (c), corresponding to seismic ground motion at Obninsk as shown in Fig. 1.

The cusp section of Fig. 2c is enlarged in Fig. 3a. Distinctive traces and episodes are sketched in Fig. $3 \mathrm{~b}$ and denoted by the letters (a) to (e). The short satellite trace (a) was just above the E region critical frequency, and the echo strength was as strong as the main trace. In contrast, the echo strength of the steep satellite traces (b) and (d) was weak compared to the main trace. The inclination of satellite trace (c) was 

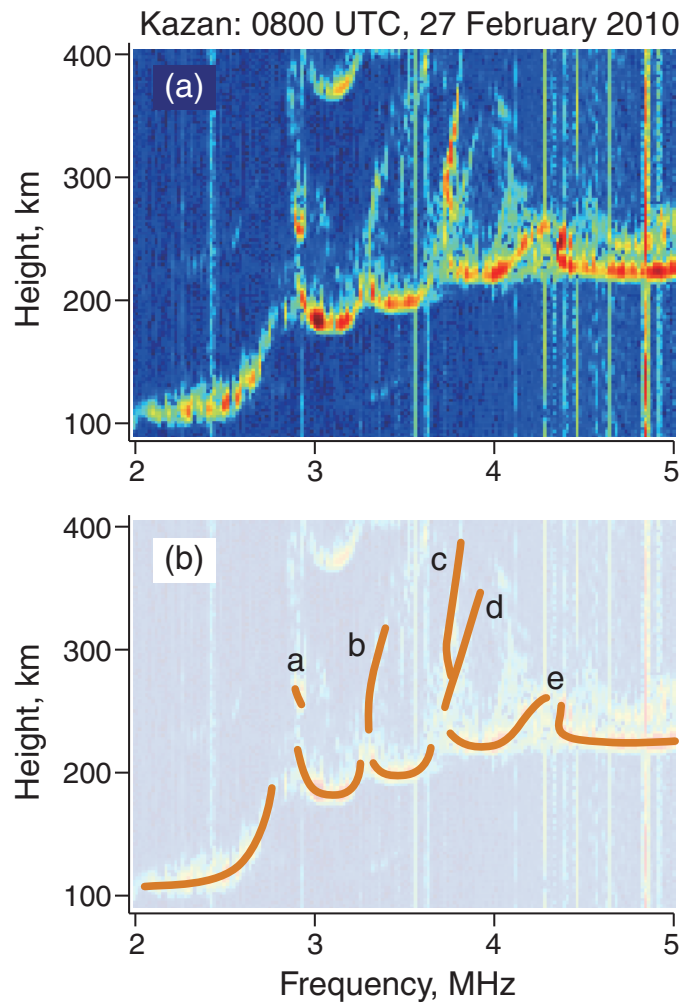

Figure 3. Enlarged ionogram showing cusp section of Fig. 2c (a) and sketch of $\mathrm{O}$-mode trace (b). Several interesting episodes are denoted by the letters (a) to (e).

steeper than that of (b) and (d), and the strength was the same as the main trace. The episode denoted by (e) was the asymmetric deformation of the main trace with a discontinuity near the top. These extreme features are not expected from the horizontally stratified density perturbation (Figs. 8 and 9 of Maruyama and Shinagawa, 2014).

\section{Analysis}

To interpret the complicated ionogram with the satellite traces and asymmetric cusp described above, tilted wavefronts induced by Rayleigh waves were considered. The velocity of the Rayleigh wave was $3.8 \mathrm{~km} \mathrm{~s}^{-1}$, as determined by the arrival time at Obninsk, and the sound speed in the thermosphere at an altitude of $150 \mathrm{~km}$ was $550 \mathrm{~m} \mathrm{~s}^{-1}$, as calculated using the atmospheric parameters from the Naval Research Laboratory Mass Spectrometer and Incoherent Scatter thermospheric model (NRLMSISE-00) (Picone et al., 2002). These velocities yield an inclination of $8^{\circ}$ for the infrasound wavefronts.
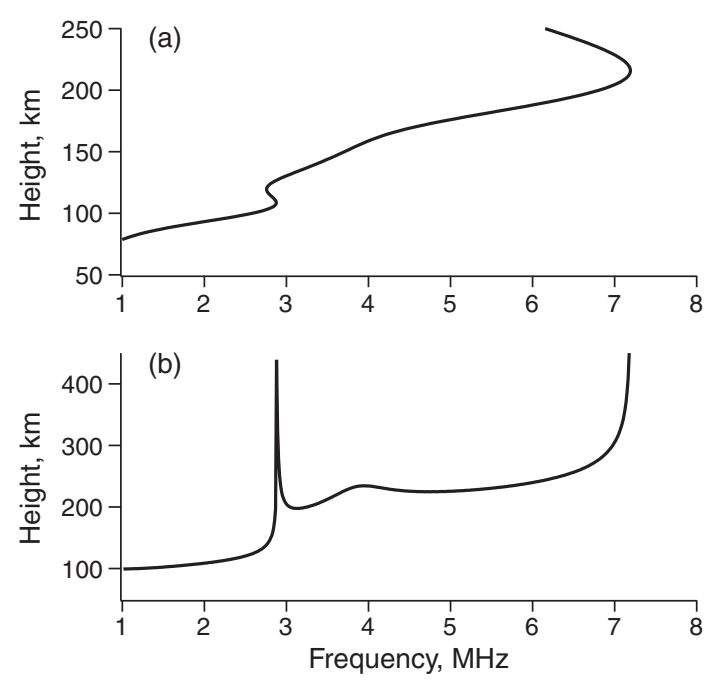

Figure 4. Electron density profile of the unperturbed ionosphere (a) and synthesized ionogram assuming vertical incidence of sounding radio waves (b).

Vertical density gradients in the F1 region of the unperturbed ionosphere are critical for the formation of cusps in the ionogram trace (Maruyama et al., 2012). For realistic simulations of a perturbed ionogram, the background ionospheric profile was numerically produced and parameters in the following equations were determined to fit the synthesized ionogram with the observed ionogram without perturbation shown in Fig. 2a. Electron density $n_{\mathrm{F} 2}$ in the principal part of the profile (F2 region) was determined by a Chapman layer (all frequencies below are in megahertz and densities are per cubic centimeter):

$$
\begin{aligned}
& n_{\mathrm{F} 2}(h)=\left(\frac{f_{\mathrm{F} 2}}{0.00898}\right)^{2} \exp \left[\frac{1}{2}\left(1-z_{\mathrm{F} 2}-e^{-z_{\mathrm{F} 2}}\right)\right], \\
& z_{\mathrm{F} 2}=\frac{h-h_{\mathrm{F} 2}}{H_{\mathrm{F} 2}} .
\end{aligned}
$$

Electron densities that represent the $\mathrm{F} 1$ and $\mathrm{E}$ regions $n_{\mathrm{F} 1}$ and $n_{\mathrm{E}}$ were given by Gaussian functions as

$$
\begin{aligned}
& n_{\mathrm{F} 1}(h)=\left(\frac{f_{\mathrm{F} 1}}{0.00898}\right)^{2} \exp \left(-z_{\mathrm{F} 1}^{2}\right), \\
& z_{\mathrm{F} 1}=\frac{h-h_{\mathrm{F} 1}}{H_{\mathrm{F} 1}} \\
& n_{\mathrm{E}}(h)=\left(\frac{f_{\mathrm{E}}}{0.00898}\right)^{2} \exp \left(-z_{\mathrm{E}}^{2}\right), \\
& z_{\mathrm{E}}=\frac{h-h_{\mathrm{E}}}{H_{\mathrm{E}}}
\end{aligned}
$$

The resultant electron density profile is

$n(h)=n_{\mathrm{F} 2}(h)+n_{\mathrm{F} 1}(h)+n_{\mathrm{E}}(h)$.

The parameters determined were $f_{\mathrm{F} 2}=6.5 \mathrm{MHz}$, $h_{\mathrm{F} 2}=223 \mathrm{~km}, H_{\mathrm{F} 2}=26 \mathrm{~km}, f_{\mathrm{F} 1}=4.1 \mathrm{MHz}, h_{\mathrm{F} 1}=176 \mathrm{~km}$, 
$H_{\mathrm{F} 1}=57 \mathrm{~km}, \quad f_{\mathrm{E}}=2.1 \mathrm{MHz}, \quad h_{\mathrm{E}}=105 \mathrm{~km}, \quad$ and $H_{\mathrm{E}}=13 \mathrm{~km}$, and the resultant electron density profile (represented by the plasma frequency) and the ionogram synthesized by assuming the vertical reflection are shown in Fig. 4a and b, respectively.

Density perturbations were modeled by considering the sound speed and Rayleigh wave parameters. Sound speed increases with altitude in the lower thermosphere. A chirp function was introduced to represent the change in wavelength as follows:

$w(h)=a(h) \sin \left[\left(\frac{h-h_{s}}{H_{s}}\right)^{4}+\alpha\right]$,

where $a(h)$ is the height variation in the perturbation amplitude proportional to the amplitude of the acoustic waves. The acoustic waves first increase with height and then decay at higher altitudes where attenuation of the waves becomes dominant due to viscosity and thermal conductivity (Maruyama and Shinagawa, 2014). These changes were expressed by a Gaussian function:

$a(h)=a_{0} \exp \left[-\left(\frac{h-h_{m}}{H_{d}}\right)^{2}\right]$,

where $a_{0}$ is the maximum perturbation amplitude (as a fraction of unperturbed density) at $h=h_{m} . H_{d}$ represents the "scale heights" of increases and decreases in the amplitude of acoustic waves. The parameters $h_{s}$ and $H_{s}$ in Eq. (8) were adjusted to place the cusps at the frequencies observed in the ionogram shown in Fig. 2c. The parameter $\alpha$ was introduced in Eq. (8) to represent the tilt of wavefronts below:

$\alpha=-2 \pi \phi / \lambda_{\mathrm{R}} \sin \theta$,

where $\phi$ is the longitude centered on the observation point (ionosonde), $\lambda_{\mathrm{R}}$ is the wavelength of the Rayleigh wave represented by the geocentric angle, and $\theta$ is the colatitudes of the observation point. The Rayleigh wave was assumed to propagate eastward (close to a great-circle direction from the epicenter to Kazan), and the wavelength was $0.82^{\circ}$, which corresponded to the surface wavelength of $91 \mathrm{~km}$ as determined from an observed period of $24 \mathrm{~s}$ and a velocity of $3.8 \mathrm{~km} \mathrm{~s}^{-1}$. The vertical profile of the density perturbation $w(h)$ above the observation point $(\alpha=0)$ for $h_{m}=150 \mathrm{~km}$ and $H_{d}=30 \mathrm{~km}$ is shown in Fig. 5. Finally, the perturbed electron density profile for ray tracing is given by

$N(h, \phi)=n(h)(1+w(h, \phi))$.

A numerical ray tracing model (Jones and Stephenson, 1975) was used to reproduce ionograms caused by the inclined wavefront irregularities described above. The magnetic dip angle and gyrofrequency were fixed at $I=72^{\circ}$ and $f_{H}=1.42 \mathrm{MHz}$, respectively. The azimuth angle of the

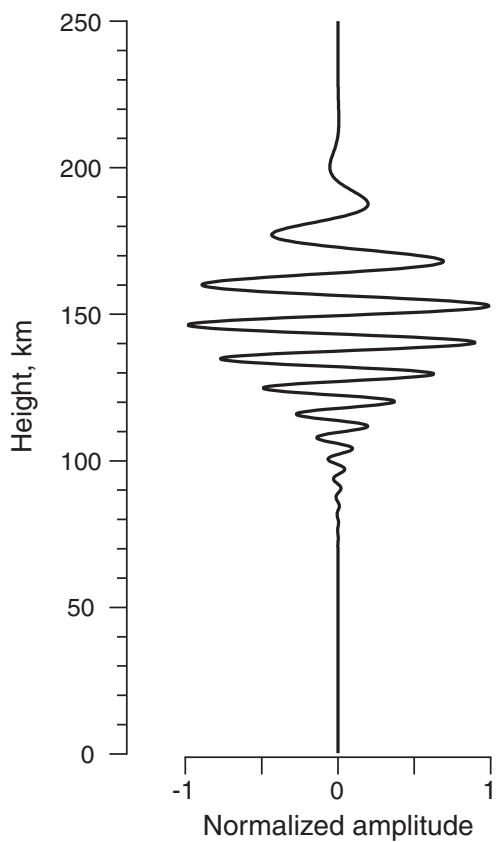

Figure 5. Waveform of electron density perturbation due to upwardpropagating acoustic waves.

initial ray direction was fixed at $270^{\circ}$ clockwise from due north, and the elevation angle was varied from 78 to $94^{\circ}$ with $0.01^{\circ}$ increments. The frequency was varied with an increment of $0.018 \mathrm{MHz}$ in accordance with the operation of the ionosonde. When rays were returned to the ground within a distance of $500 \mathrm{~m}$ from the transmitter (ionosonde), the virtual heights were obtained as half the group paths.

\section{Results and discussion}

Ionograms synthesized by ray tracing are shown in Fig. 6 for various perturbation amplitudes $a_{0}$. Virtual heights for all rays that returned to the transmitter (ionosonde) are plotted with short vertical bars representing the finite pulse width of the ionosonde. Figure $6 a$ is the ionogram for the unperturbed electron density corresponding to Fig. 2a and is identical to Fig. $4 b$, which was derived without ray tracing. Figure $6 \mathrm{~b}$ shows the ionogram for the maximum perturbation amplitude of $1 \%$. Three moderate cusps were formed, similar to Fig. 2b, with each cusp being symmetric with respect to the frequency that gives the maximum virtual height. Figure $6 c$ shows the ionogram when the maximum perturbation amplitude was increased to $4 \%$. When compared to Fig. 3, distinctive traces were observed to be reproduced, except for (c) and the break in (e). Episodes (a), (b), and (d) are characterized by multipathing. The break in episode (e), however, may be characterized by the dissipation of radio wave energy or defocusing of the ray. For further interpretation of the complex 

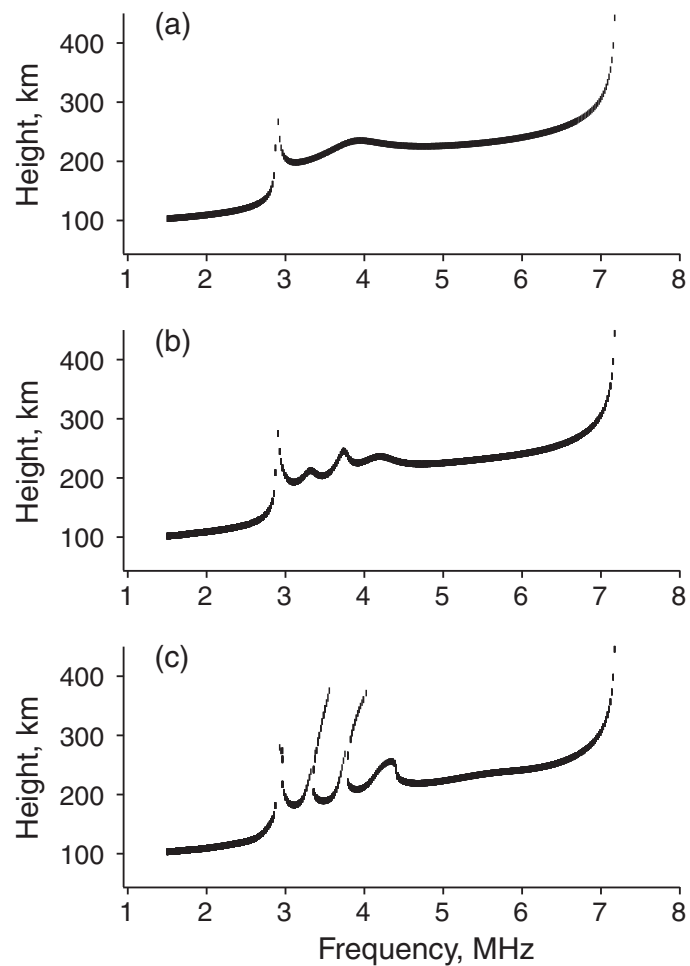

Figure 6. Synthesized ionograms using ray tracing for unperturbed density profile (a), maximum density perturbation of $1 \%$ (b), and $4 \%$ (c).

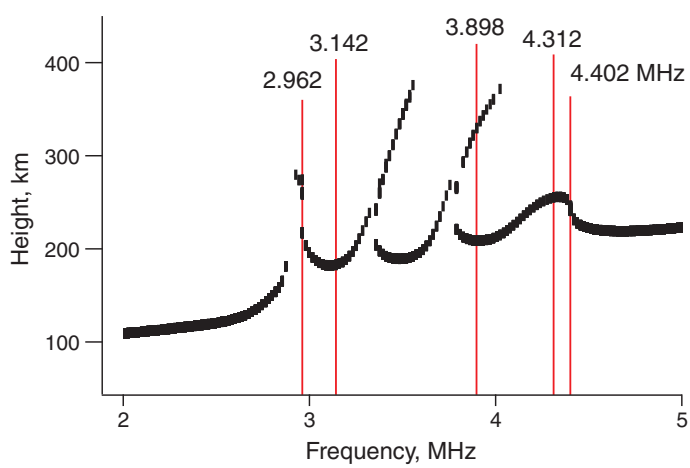

Figure 7. Enlarged synthesized ionogram with maximum density perturbation of $4 \%$. Individual rays with various initial elevation angles were analyzed at the frequencies denoted by the vertical red lines and are shown in Figs. 8 to 11.

ionogram of Fig. 6c, individual ray paths were analyzed at selected frequencies as shown in Fig. 7.

Figure 8 shows ray paths for the elevation angles from 80 to $94^{\circ}$ in increments of $0.2^{\circ}$ at $3.142 \mathrm{MHz}$, where the main trace alone was observed in Fig. 3 and reproduced in Fig. 7. The ray paths varied smoothly with the elevation angle and the ray returned to the ionosonde at an elevation angle of $91.2^{\circ}$, which is shown by the red line in the figure.

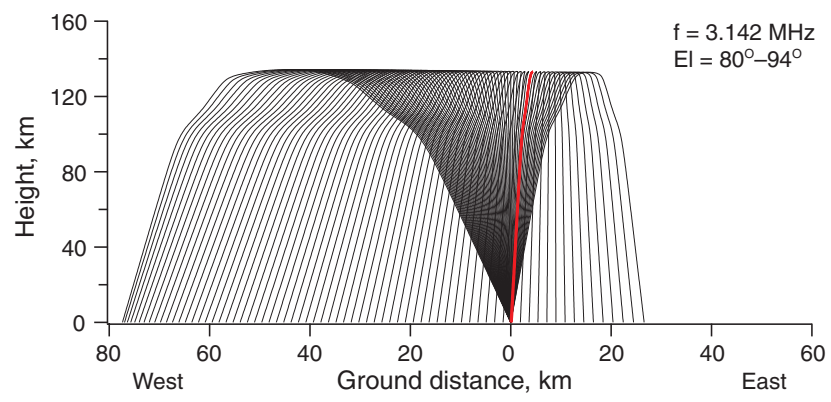

Figure 8. Ray plots for initial elevation angles from 80 to $94^{\circ}$ with increments of $0.2^{\circ}$ at a frequency of $3.142 \mathrm{MHz}$. Red line shows a ray path that returned to the receiver (ionosonde).
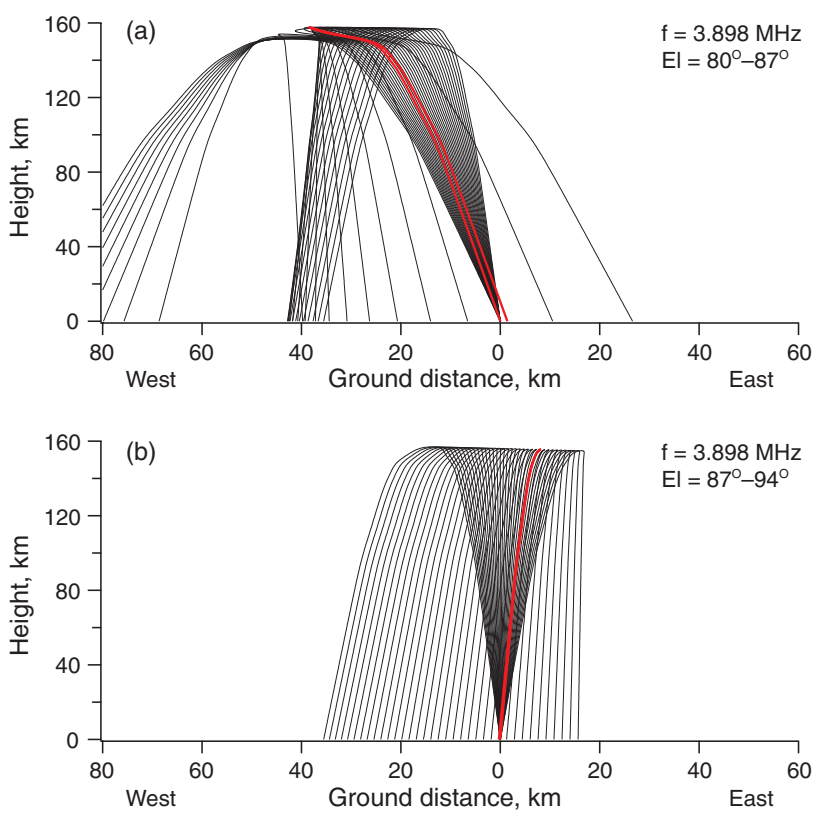

Figure 9. Ray plots for initial elevation angles from 80 to $87^{\circ}$ (a) and 87 to $94^{\circ}$ (b) with increments of $0.2^{\circ}$ at a frequency of $3.898 \mathrm{MHz}$. Red lines show ray paths that returned to the receiver (ionosonde).

Focusing of the ray paths is noted roughly $75 \mathrm{~km}$ west of the ionosonde.

Figure 9 shows ray paths at $3.898 \mathrm{MHz}$, where a steep satellite trace was observed. Because the ray paths are complex, rays for low- $\left(80\right.$ to $\left.87^{\circ}\right)$ and high- $\left(87\right.$ to $\left.94^{\circ}\right)$ elevation angles are shown separately in Fig. 9a and b, respectively. The ray paths for the low-elevation angles in Fig. 9a changed erratically and scattered at elevation angles between 81.8 and $\sim 84^{\circ}$. An oblique return occurred at $82.4^{\circ}$ as indicated by the red line. The ray path of the oblique return bent largely to the west near an altitude of $150 \mathrm{~km}$, just below the reflection height $(\sim 158 \mathrm{~km})$, yielding a large delay in radio wave propagation that was responsible for the steep satellite trace with large virtual heights. In contrast to the low-elevation rays, the 


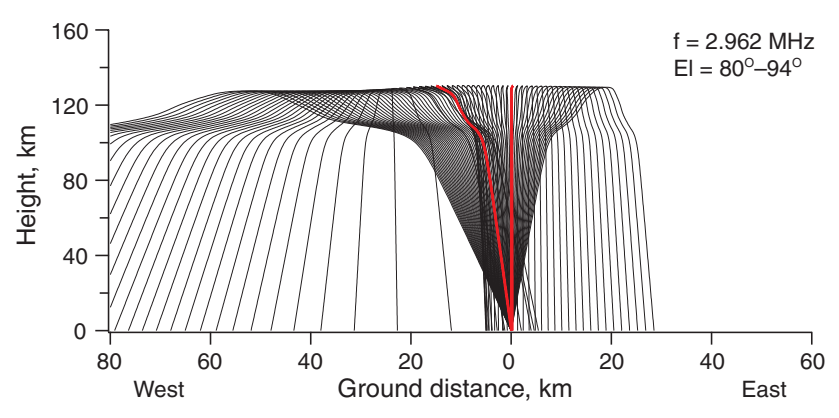

Figure 10. Ray plots for initial elevation angles from 80 to $94^{\circ}$ with increments of $0.2^{\circ}$ at a frequency of $2.962 \mathrm{MHz}$. Red lines show ray paths that returned to the receiver (ionosonde).

high-elevation rays shown in Fig. 9b were similar to those of Fig. 8 , and a near-vertical return occurred at $92^{\circ}$. The density of rays around the oblique and near-vertical returns can be a measure of the strength of the received signals. Unlike the high-elevation rays, the rays around the oblique return were defocused in the vicinity of zero ground range, which agrees with the low strength of the satellite traces (cool colors) as shown in Fig. 3a.

Figure 10 shows ray paths at $2.962 \mathrm{MHz}$, just above foE, which corresponds to episode (a) shown in Fig. 3b. Both low- and high-elevation rays are plotted in the same figure and oblique and near-vertical returns are indicated by the red lines. The large bend of the rays near $105 \mathrm{~km}$ was due to the E-F valley of the electron density profile. Rays with elevation angles less than $85.6^{\circ}$ were reflected to the west, whereas rays with higher angles and those lower than $90^{\circ}$ were reflected back. The back-reflected rays did not go largely eastward but instead were focused around the zero ground range, in contrast with the defocused oblique rays in Fig. 9a. The focusing of the oblique rays agrees with the intense satellite echoes of episode (a) in Fig. 3a.

Figure 11 shows ray paths at two closely separated frequencies. At $4.312 \mathrm{MHz}$, strong focusing occurred at ground distances near $20 \mathrm{~km}$ east and defocusing over the range from $40 \mathrm{~km}$ west to $20 \mathrm{~km}$ east, as shown in Fig. 11a. The focusing area moved westward as frequency increased and reached the ionosonde at $4.402 \mathrm{MHz}$ as shown in Fig. 11b. This comparison supports intensity modulation of the ionogram trace, which partially explains the break in the trace in episode (e).

As presented above, most of the characteristics of the anomalous ionogram can be explained by considering the inclined wavefronts of density perturbation. However, reproducing the most significant episode (c) failed. This satellite trace was steeper than the others and the intensity was as high as the main trace. The high intensity of the signals suggests focusing of rays. The long-period Airy phase with a period of several minutes is well known to cause variation in total electron content (Calais and Minster, 1995; Ducic et al., 2003; Astafyeva et al., 2009; Tsugawa et al., 2011). This compo-
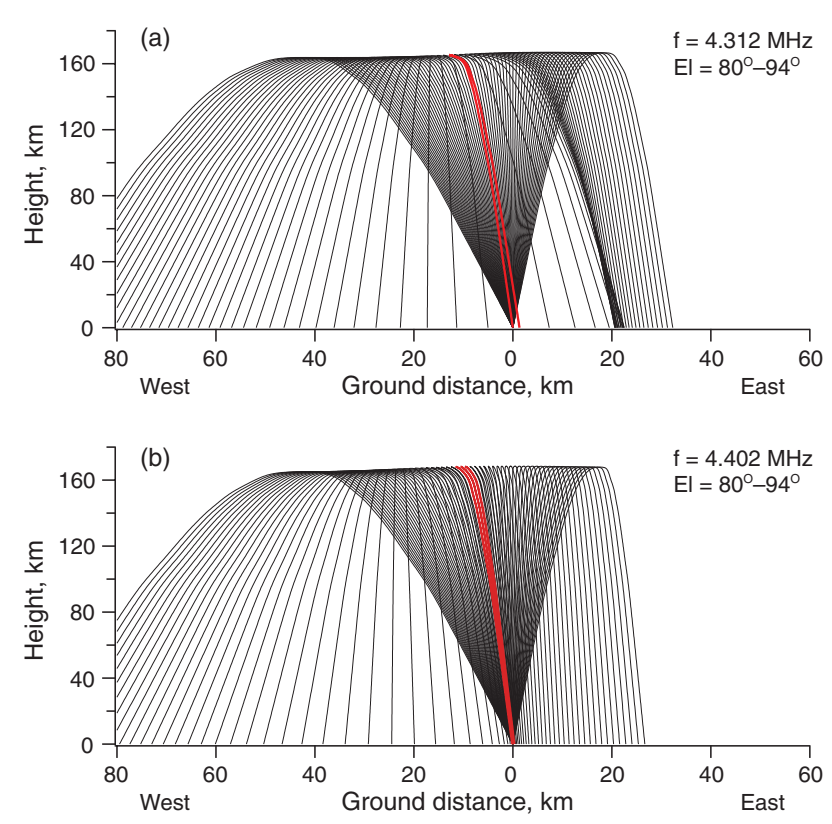

Figure 11. Ray plots for initial elevation angles from 80 to $94^{\circ}$ with increments of $0.2^{\circ}$ at frequencies of $4.312 \mathrm{MHz}$ (a) and $4.402 \mathrm{MHz}$ (b). Red lines show ray paths that returned to the receiver (ionosonde).

nent of disturbance is not clearly visible in ionograms because the vertical wavelengths are much longer than the ionospheric layer thickness. However, large-scale up and down motion with long horizontal and vertical wavelengths is possible (Nishitani et al., 2011; Ogawa et al., 2012), and this was not considered here. An elaborate perturbation model is required that allows the focusing of long-range rays, such as a combined effect of short- and long-period Airy phases of Rayleigh waves, which was not taken into account for this study.

Such highly deformed ionograms with slant satellite traces as examined in this paper are a rare occurrence. However, when previously examined coseismic ionogram disturbances after 1957 (Maruyama et al., 2012; Maruyama and Shinagawa, 2014) were revisited, a similar effect was identified in two ionograms obtained at ionosonde sites in Japan. Two ionograms were shown in Figs. $2 \mathrm{~d}$ and $3 \mathrm{~b}$ of Maruyama and Shinagawa (2014), and their cusp sections are reproduced in Fig. 12a and b, respectively. The ionogram in Fig. 12a was obtained at Yamagawa $\left(31.20^{\circ} \mathrm{N}, 130.62^{\circ} \mathrm{E}\right.$; epicentral distance $1124 \mathrm{~km})$ after the $M 7.7$ aftershock $\left(36.12^{\circ} \mathrm{N}\right.$, $141.25^{\circ} \mathrm{E}$ ) of the 2011 Tohoku-oki earthquake in Japan. A prominent feature is a fishhook-shaped echo trace at around 4.5 MHz with discontinuities at its lower and higher frequencies, which was interpreted as the disappearance of the left half of cusps due to defocusing like in Fig. 11a. The cusps at $3.5,3.8$, and $4.1 \mathrm{MHz}$ were observed to be accompanied by satellite traces of oblique echoes, although they were not 


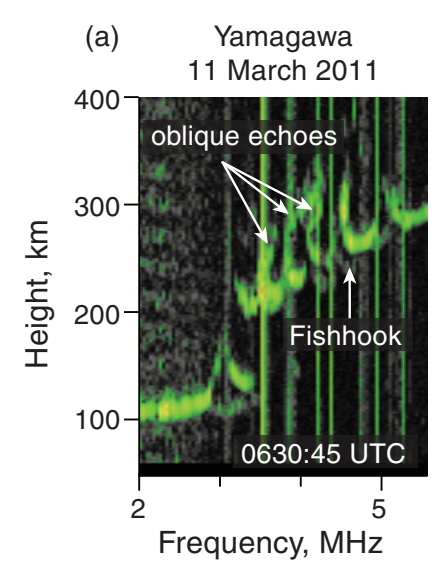

Figure 12. Ionograms obtained at Yamagawa after the $M 7.7$ aftershock of the 2011 Tohoku-oki earthquake (a) and at Wakkanai after the $M 9.0$ main shock of the same earthquake (b).

very clear due to intense interferences (vertical lines). The ionogram in Fig. $12 \mathrm{~b}$ was obtained at Wakkanai $\left(45.16^{\circ} \mathrm{N}\right.$, $141.75^{\circ} \mathrm{E}$; epicentral distance $790 \mathrm{~km}$ ) after the $M 9.0$ main shock $\left(38.10^{\circ} \mathrm{N}, 142.86^{\circ} \mathrm{E}\right)$ of the 2011 Tohoku-oki earthquake. Oblique returns were clearly observed at frequencies between 3.5 and 3.8 MHz. However, those echoes did not form a single slant trace, but the trace fragmented into three as indicated by the arrows. The seismic ground motion responsible for this event was less monochromatic and was composed of several frequency components (Fig. 7c of Maruyama and Shinagawa, 2014) because of the short epicentral distance, which probably resulted in the modulation of the oblique echo trace.

A question may arise as to why there was a rare observation of ionograms with slant satellite traces even after a larger earthquake and closer distances such as the 2011 M 9.0 Tohoku-oki earthquake and the Japanese ionosonde chain with epicentral distances $<2000 \mathrm{~km}$. These ionosondes were operated at intervals of $15 \mathrm{~min}$, and major ionospheric events must have occurred between the times of ionogram acquisition as described by Maruyama and Shinagawa (2014). Unlike the Japanese ionosondes, the ionosonde at Kazan was operated at $1 \mathrm{~min}$ intervals and did not miss the major disturbances yielding slant satellite traces induced by the distant earthquake in Chile.

\section{Summary}

A significant anomaly was observed in the ionogram trace at Kazan, Russia, following the 2010 M 8.8 Chile earthquake, which was caused by vertical ground motions associated with Rayleigh waves and the resulting acoustic waves that propagated upward. The anomaly was characterized by steep satellite traces for which the range increased rapidly with frequency, starting near the top of the cusps of the main trace

and continuing for $0.1-0.2 \mathrm{MHz}$. This complicated ionogram was analyzed by applying a ray tracing technique to a perturbed ionospheric density model, which took account of the finite Rayleigh wave velocity and sound speed in the thermosphere. Wavefronts of acoustic waves and induced density perturbations were inclined by $\sim 8^{\circ}$.

The inclined density perturbation caused oblique returns of sounding radio waves in addition to the nearly vertical returns of the main trace. The oblique ray paths bent further from the vertical, just below the reflection level where the group velocity of the radio waves lowers, yielding a large delay in the radio pulse of the ionosonde responsible for the steep satellite traces. In association with the changes in ray paths, focusing and defocusing of the sounding radio waves occurred in agreement with variations in the intensity of the ionogram trace.

Although many of the characteristics of the anomalous ionogram trace were explained by considering the inclined wavefronts of density perturbation, the ray tracing as applied to the density model failed to reproduce one episode of a steep satellite trace with a high intensity that was similar to the main trace. An elaborate perturbation model is required that allows the focusing of long range rays, such as those that occur as a combined effect of the short- and long-period Airy phases of Rayleigh waves, a process that was not taken into account in this study.

Acknowledgements. The work at Kazan Federal University was conducted as part of the Russian Government Program of Competitive Growth of Kazan Federal University. The broadband seismogram was obtained from the IRIS website at http://www.iris.edu/ wilber3/find_event.

The topical editor, K. Hosokawa, thanks K. J. W. Lynn and one anonymous referee for help in evaluating this paper.

\section{References}

Astafyeva, E., Heki, K., Kiryushkin, V., Afraimovich, E., and Shalimov, S.: Two-mode long-distance propagation of coseismic ionosphere disturbances, J. Geophys. Res., 114, A10307, doi:10.1029/2008JA013853, 2009.

Blanc, E.: Observations in the upper atmosphere of infrasonic waves from natural or artificial sources: A summary, Ann. Geophys., 3, 673-688, 1985.

Calais, E. and Minster, J. B.: GPS detection of ionospheric perturbations following the January 17, 1994, Northridge earthquake, Geophys. Res. Lett., 229, 1045-1048, 1995.

Capon, J.: Analysis of Rayleigh-wave multipath propagation at LASA, Bull. Seismol. Soc. Am., 60, 1701-1731, 1970.

Chum, J., F. Hruska, J. Zednik, and J. Lastovicka: Ionospheric disturbances (infrasound waves) over the Czech Republic excited by the 2011 Tohoku earthquake, J. Geophys. Res., 117, A08319, doi:10.1029/2012JA017767, 2012. 
Ducic, V., Artru, J., and Lognonné, P.: Ionospheric remote sensing of the Denali Earthquake Rayleigh surface waves, Geophys. Res. Lett., 30, 1951, doi:10.1029/2003GL017812, 2003.

Jones, R. M. and Stephenson, J. J.: A versatile three-dimensional ray tracing computer program, Office of Telecommunications Report 75-076, US Government Printing Office, Washington DC, USA, 1975.

Leonard, R. S. and Barnes, R. A.: Observation of ionospheric disturbances following the Alaska earthquake, J. Geophys. Res., 70, 1250-1253, 1965.

Maruyama, T. and Shinagawa, H.: Infrasonic sounds excited by seismic waves of the 2011 Tohoku-oki earthquake as visualized in ionograms, J. Geophys. Res.-Space, 119, 4094-4108, doi:10.1002/2013JA019707, 2014.

Maruyama, T., Tsugawa, T., Kato, H., Saito, A., Otsuka, Y., and Nishioka, M.: Ionospheric multiple stratifications and irregularities induced by the 2011 off the Pacific coast of Tohoku Earthquake, Earth Planets Space, 63, 869-873, 2011.

Maruyama, T., Tsugawa, T., Kato, H., Ishii, M., and Nishioka, M.: Rayleigh wave signature in ionograms induced by strong earthquakes, J. Geophys. Res., 117, A08306, doi:10.1029/2012JA017952, 2012.

Maruyama, T., Yusupov, K., and Akchurin, A.: Ionosonde tracking of infrasound wavefronts in the thermosphere launched by seismic waves after the 2010 M8.8 Chile earthquake J. Geophys. Res., in review, 2016.

Nishitani, N., Ogawa, T., Otsuka, Y., Hosokawa, K., and Hori, T.: Propagation of large amplitude ionospheric disturbances with velocity dispersion observed by the SuperDARN Hokkaido radar after the 2011 off the Pacific coast of Tohoku Earthquake, Earth Planets Space, 63, 891-896, 2011.
Ogawa, T., Nishitani, N., Tsugawa, T., and Shiokawa, K.: Giant ionospheric disturbances observed with the SuperDARN Hokkaido HF radar and GPS network after the 2011 Tohoku earthquake, Earth Planets Space, 64, 1295-1307, 2012.

Oliver, J.: A summary of observed seismic surface wave dispersion, Bull. Seismol. Soc. Am., 52, 81-86, 1962.

Picone, J. M., Hedin, A. E., Drob, D. P., and Aikin, A. C.: NRLMSISE-00 empirical model of the atmosphere: Statistical comparisons and scientific issues, J. Geophs. Res., 107, 1468, doi:10.1029/2002JA009430, 2002.

Rolland, L. M., Lognonné, P., and Munekane, H.: Detection and modeling of Rayleigh wave induced patterns in the ionosphere, J. Geophys. Res., 116, A05320, doi:10.1029/2010JA016060, 2011.

Tanaka, T., Ichinose, T., Okuzawa, T., Shibata, T., Sato, Y., Nagasawa, C., and Ogawa, T.: HF-Doppler observations of acoustic waves excited by the Urakawa-Oki earthquake on 21 March 1982, J. Atmos. Terr. Phys., 46, 233-245, 1984.

Tsugawa, T., Saito, A., Otsuka, Y., Nishioka, M.,. Maruyama, T, Kato, H., Nagatsuma, T., and Murata, K. T.: Ionospheric disturbances detected by GPS total electron content observation after the 2011 off the Pacific coast of Tohoku Earthquake, Earth Planets Space, 63, 875-879, 2011.

Yuen, P. C., Weaver, P. F., Suzuki, R. K., and Furumoto, A. S.: Continuous, traveling coupling between seismic waves and the ionosphere evident in May 1968 Japan earthquake data, J. Geophys. Res., 74, 2256-2264, 1969. 